УДК 338.24.01

JEL Classification: Q57

АСАДУЛЛИНА Н. $\mathbf{P}^{1}$

\title{
КОМПЛЕКСНАЯ ОЦЕНКА КОНКУРЕНТОСПОСОБНОСТИ ПЕРЕРАБОТАННОЙ ПЛОДООВОЩНОЙ ПРОДУКЦИИ
}

\author{
DOI: 10.32620/cher.2019.1.01
}

Постановка проблемы. В статье отображена оценка конкурентоспособности переработанной плодоовощной продукции, обоснованы качественные характеристики плодоовощной продукции, а также даны параметры степени согласованности мнений экспертов на основе расчета коэффициента конкордации. Цель статьи - отобразить и охарактеризовать существующие методики комплексной оценки конкурентоспособности переработанной плодоовощной продукции. Объект исследования - процесс определения качества производимой продукции, а также конкурентоспособности переработанной плодоовощной продукции. Meтодbl, использованные в исследовании - логичекий, сравнительный, аналитический, научно-методологический. Гипотеза исследования состоит в предположении наличия зависимости конкурентоспособности переработанной плодоовощной продукции и объемов ее продаж. Изложение основного материала. Предпочтение покупатель отдает продукции в зависимости от назначения использования этого продукта. При дальнейшей ее переработке покупатель обращает внимание на объем фасовки, пригодность тары для содержания продукта в ней, а так же предельные сроки хранения продукции. В статье предложены такие показатели качества переработанной плодоовощной продукции: биохимический состав продукции; фасовка продукции; дизайн и оформления продукции; внешний вид и консистенция; строк годности товара; стоимость производства одного килограмма продукции. Оригинальность и практическое значение исследования состоит в том, что автор обосновывает степень влияния предложенных показателей на конкурентоспособность на основе экспертных оценок. Число баллов устанавливается в зависимости от количества учитываемых факторов. Степень согласованности мнений экспертов устанавливается на основе расчета коэффициента конкордации. Bыводы исследования. В процессе фасовки товара и его производства необходимо учитывать направления его использования. Для дальнейшего промышленного потребления переработанная плодоовощная продукция может быть изготовлена с более высоким содержанием сухих растворимых веществ, витаминов, сахаров, кислотности. Это позволит сэкономить затраты на таре, транспортных расходах, на погрузочно-разгрузочных операциях.

Ключевые слова:

конкурентоспособность, плодоовощная продукция, коэффициент конкордации, эксперт, сроки хранения продукции.

\section{COMPLEX ESTIMATION OF COMPETITIVENESS OF OVERWORKED FRUIT AND VEGETABLE PRODUCTION}

Formulation of the problem. The article reflects the assessment of the competitiveness of processed fruit and vegetable products, the qualitative characteristics of fruit and vegetable products are substantiated, as well as the parameters of the degree of consistency of expert opinions based on the calculation of the concordance coefficient. The purpose of the research is to reflect and characterize existing methods of integrated assessment of the competitiveness of processed fruit and vegetable products. The object of research - the process of determining the quality of products produced, as well as the competitiveness of processed fruit and vegetable products. The methods used in the research - logical, comparative, analytical, scientific and methodological. The hypothesis of the research is to assume the dependence of the competitiveness of processed fruit and vegetable products and its sales volumes. The statement of basic materials. The buyer prefers products depending on the purpose and use of this product. In the course of further processing, the buyer pays attention to the volume of packaging, the suitability of the packaging for the content of the product in it, the maximum time for the storage of products. The article suggests such indicators of quality of processed fruit and vegetable production: biochemical composition of products; packaging of products; design and design of products; appearance and consistency; terms of product suitability; cost of production per kilogram of production. The originality and practical significance of

${ }^{1}$ Асадулліна Наіля Рамілівна, канд. екон. наук, доцент кафедри «Економіка праці та управління», Ташкентська філія «Російський економічний університет ім. Г. В. Плеханова», Ташкент, Узбекистан.

Asadullina Nailya, Ph.D. in Economics, Associate Professor of Economics Labor and Management Department Tashkent branch «Russian Economic University named G. V. Plekhanov», Tashkent, Uzbekistan.

ORCID ID: 0000-0001-7022-3638

e-mail: rasadullina@mail.ru 
the research is that the author substantiates the degree of influence of the proposed indicators on competitiveness on the basis of expert assessments. The number of points is determined depending on the number of factors considered. The degree of consensus of expert opinions is established on the basis of calculating the coefficient of concordation. Conclusions of the research. In the process of packaging the product and its production must take into account the directions of its use. For further industrial consumption, processed fruit and vegetable products can be made with a higher content of dry soluble substances, vitamins, sugars, and acidity. This will save on the cost of packaging, transport costs, and handling operations.

Key words:

competitiveness, fruit and vegetable production, coefficient of concordation, expert, terms of product storage.

\section{КОМПЛЕКСНА ОЦІНКА КОНКУРЕНТОСПРОМОЖНОСТІ ПЕРЕРОБЛЕНОЇ ПЛОДООВОЧЕВОЇ ПРОДУКЦІї}

Постановка проблеми. У статті відображена оцінка конкурентоспроможності переробленої плодоовочевої продукції, обгрунтовані якісні характеристики плодоовочевої продукції, а також дані параметри ступеня узгодженості думок експертів на основі розрахунку коефіцієнта конкордації. Meта cmammi відображення та характеристика існуючих методик комплексної оцінки конкурентоспроможності переробленої плодоовочевої продукції. Об'єкт дослідження - процес визначення якості продукції, що виробляється, а також конкурентоспроможності переробленої плодоовочевої продукції. Методи, використані в дослідженні - логичеких, порівняльний, аналітичний, науково-методологічний. Гіпотеза дослідження полягає в припущенні наявності залежності конкурентоспроможності переробленої плодоовочевої продукції та обсягів ії продажів. Виклад основного матеріалу. Перевагу покупець віддає продукції в залежності від призначення та використання цієї продукції. При подальшій iï переробці покупець звертає увагу на обсяг фасування, придатність тари для утримання продукту в ній, граничні терміни зберігання продукції. У статті запропоновані такі показники якості переробленої плодоовочевої продукції: біохімічний склад продукції; фасування продукції; дизайн та оформлення продукції; зовнішній вигляд і консистенція; строки придатності товару; вартість виробництва одного кілограму продукції. Оригінальність $і$ практичне значення дослідження полягає в тому, що автор обгрунтовує ступінь впливу запропонованих показників на конкурентоспроможність на основі експертних оцінок. Число балів встановлюється в залежності від кількості врахованих чинників. Ступінь узгодженості думок експертів встановлюється на основі розрахунку коефіцієнта конкордації. Висновки дослідження. В процесі фасування товару і його виробництва необхідно враховувати напрямки його використання. Для подальшого промислового споживання перероблена плодоовочева продукція може бути виготовлена з більш високим вмістом сухих розчинних речовин, вітамінів, цукрів, кислотності. Це дозволить заощадити витрати на тарі, транспортних витратах, на вантажно-розвантажувальних операціях.

\section{Ключові слова:}

конкурентоспроможність, плодоовочева продукція, коефіцієнт конкордації, експерт, терміни зберігання продукції.

Постановка проблемы. В условиях модернизации и диверсификации экономики Узбекистана усиливается взаимосвязь развития предприятий плодоовощного комплекса, которые определяют требования к конкуренции товарной политики в отношении, объемов и качества выпускаемой продукции.

Любой товар, вынесенный на рынок, фактически проходит там проверку на степень удовлетворения общественных потребностей: каждый покупатель приобретает тот товар, который наиболее полно удовлетворяет его личные потребности, а масса покупателей - тот, который более полно соответствует общественным потребностям, нежели товары - конкуренты.

Анализ последних исследований и публикаций. Конкуренция - одна из основных черт рыночного хозяйства, обеспечива- ющая творческую свободу личности, создающая условия для самореализации сферы экономики путем разработки и создания новых конкурентоспособных товаров и услуг. Под конкурентоспособностью товаров или услуг понимается комплекс потребительских, ценовых и качественных характеристик товаров и услуг, определяющих их успех на мировом и внутреннем рынках [1]. Конкурентоспособность товара или услуг можно определить только в сравнении с аналогами, произведенными мировыми лидерами данной сферы.

В Республике получают широкое развитие фермерские и дехканские хозяйства, отличающиеся малыми объемами производства [2]. Это существенно усложняет обеспечение промышленных предприятий (большой мощности) сырьевыми ресурсами из-за роста 
стоимости перевозок, повышая долю транспортных затрат в общей стоимости продукции.

Кроме того, дехканские и фермерские хозяйства реализуют свою продукцию по ценам, установившимся на данный момент на рынке, по которой промышленное предприятие купить не может. В результате на промышленную переработку поступают сырьевые ресурсы, не востребованные рынком, то есть предприятие снабжается по остаточному принципу. Сельскохозяйственные предприятия, фермерские и дехканские хозяйства, имеющие контракт на поставку продукции обязаны 30\% его объема поставить перерабатывающим предприятиям [3].

Цель статьи - отобразить и охарактеризовать существующие методики комплексной оценки конкурентоспособности переработанной плодоовощной продукции.

Изложение основого материала исследования. Отсутствие качественных параметров сырьевых ресурсов в контрактах создает условия, при которых производитель сельскохозяйственной продукции реализует его сторонним покупателям по более высокой цене, а в переработку сдается продукция, не востребованная рынком. Естественно в этих условиях качество сырьевых ресурсов далеки от требований предприятия.

Основные требования к качеству сырьевых ресурсов установлены ГОСТом 3343 89 , в соответствии с которым томаты, поступающие на переработку должны иметь сухих растворимых веществ $28-32 \%$, содержание нитратов не должно превышать 50-60 млгр. $\%$, титруемых кислот не более $10 \%$, доля хлоридов не должна превышать $1,5 \%$ всей массы продукции, что обуславливает низкий процент содержания данного вещества в исходном сырьевом материале. Кроме того, уделяется особое внимание содержанию в сырьевых ресурсах тяжелых металлов. Их содержание в килограмме сырья не должно быть более: 200 мг- олова; свинца- 1 мг; кадмия -0,05 мг; ртути-0,02 мг; меди -5 мг; цинка -10 мг; мышьяка -0,2 мг. Выше перечисленные факторы определяют качество произведенной промышленной продукции.

В силу различий климатических условий по территории Узбекистана, почвы по состоянию, характеризующимися бонитетом, существенно отличаются, что является причиной изменчивости качества сырья. Однако на качество сырьевых ресурсов существенное влияние оказывает и периоды съема урожая. В начале сезона кислотность составляет $7,8 \%$, а в конце $11 \%$. В начале сезона урожай отличается повышенным содержанием воды.

Выше указанные факторы влекут за собой рост затрат при переработке сырья. Увеличению затрат также способствуют разрозненность всей логистической цепи, призванной обеспечивать рынок качественной продукцией перерабатывающей промышленности. Исследованиями авторов установлено, что в этом случае расходы электроэнергии увеличиваются в среднем на $20 \%$, воды 10 $15 \%$, труда $20 \%$, сырья 5-6\%.

Наряду с этим, в целях сокращения разрыва между сахаристостью и кислотностью сырьевых ресурсов при переработке добавляется сахар, что способствует доведению качественных параметров продукции до требований ГОСТА, при увеличении стоимости производства. Промышленные предприятия, производящие томат - пасту, не добавляют сахар в продукцию, так как это связано с высокой стоимостью продукции и потерей ею доли конкурентоспособности по ценовому фактору. Необходимо отметить, что высокой кислотностью выделяется продукция, произведенная из помидор позднего срока сбора, у которой титрируемая кислотность составляет 11 и более процентов. Не доводя продукцию до требований ГОСТА по кислотности, перерабатывающее предприятие перекладывает часть своих затрат на плечи других предприятий, для которых томат паста служит сырьевыми ресурсами.

При поступлении сырья на переработку осуществляется сортировка по степени зрелости и зараженности вредителями. На этой стадии, как показали исследования, выбраковывается и передается на корм скоту еще $30 \%$ поступивших сырьевых ресурсов, что повышает удельные затраты сырьевых ресурсов на производство единицы продукции, что существенно понижает конкурентоспособность произведенной продукции на мировых рынках.

Конкурентоспособность той или иной продукции должна определятся качественными характеристиками самой продукции, а не другими параметрами. Ряд авторов конкурентоспособность продукции устанавливают на основе индекса продаж [1]. По нашему мнению, такая оценка не соответствует действительности в виду того, что реализация 
продукции на рынке зависит от состояния рынка, качества товара, цены на него.

Конкурентоспособность товара можно определить в несколько этапов. На первом этапе устанавливается перечень показателей, по которым будет оценена конкурентоспособность отечественной продукции и эталона, затем - степень влияния каждого показателя на конкурентоспособность и определяется его весовое значение.

Конкурентоспособность продукции определяется по значительному кругу показателей, таких как: качество поступающих на предприятие сырьевых ресурсов; материалоемкость единицы продукции; себестоимость производства, экономичность переработки и дизайн, то есть обеспеченность упаковочными материалами, наклейками и др. Кроме того, первые три показателя оказывают существенное влияние на себестоимость произведенной продукции, а следовательно, на ее цену.

Предпочтение покупатель отдает продукции в зависимости от назначения использования этого продукта. При дальнейшей ее переработке покупатель обращает внимание, в первую очередь, на объем фасовки, пригодность тары для содержания продукта в ней, а так же предельные сроки хранения данной продукции. Таким образом, покупатель обращает внимание на внешний вид и консистенцию товара. Если покупка совершена для конечного потребления, обращается особое внимание на объемы, фасовку, срок годности продукта, консистенцию товара, дизайн и форму упаковки произведенной продукции. Исходя из выше сказанного, нами приняты следующие показатели качества томат пасты:

- биохимический состав продукции;

- фасовка продукции;
- дизайн и оформления продукции;

- внешний вид и консистенция;

- строк годности товара;

- стоимость производства одного килограмма томат пасты.

Отметим, что предлагаемый перечень показателей, характеризующих качество продукции, оставляет широкое поле для полемики. Однако и этот вариант имеет право на существование при определении конкурентоспособности.

Степень влияния вышеприведенных показателей на конкурентоспособность устанавливается на основе экспертных оценок. Для этих целей, эксперты присваивают каждому фактору баллы, в зависимости от степени влияния его на конкурентоспособность. Число баллов устанавливается в зависимости от количества учитываемых факторов. При высокой степени влияния фактора на конкурентоспособность ему присваивается большее число баллов. Использовать результаты оценок экспертов возможно лишь в том случае, если мнения экспертов согласуются. Степень согласованности мнений экспертов устанавливается на основе расчета коэффициента конкордации, определяемого по формуле (1):

$$
\mathrm{W}=12 \mathrm{~S} / \mathrm{m}^{2}\left(\mathrm{n}^{3}-\mathrm{n}\right),
$$

где : $\mathrm{m}$ - количество факторов, влияющих на конкурентоспособность продукции; $\mathrm{n}$ - число наблюдений;

$\mathrm{S}$ - сумма квадратов отклонений рангов.

$$
S=\sum_{1}^{n} r^{2}-\frac{\left(\sum_{1}^{m} \sum_{1}^{n}\right)^{2}}{m},
$$

Баллы, выставленные независимыми экспертами приведены в табл. 1.

Т а б ли ца 1

Определение степени согласованности мнений экспертов

\begin{tabular}{|l|c|c|c|c|c|c|c|}
\hline \multicolumn{1}{|c|}{\begin{tabular}{l} 
Единичные показатели \\
\multicolumn{1}{|c|}{ качества }
\end{tabular}} & 1 & 2 & 3 & 4 & 5 & 6 & \multirow{2}{*}{ Итого } \\
\cline { 2 - 7 } & 5 & 5 & 5 & 4 & 4 & 5 & 28 \\
\hline $\begin{array}{l}\text { Пиохимический состав } \\
\text { продукции }\end{array}$ & 3 & 3 & 2 & 3 & 3 & 3 & 17 \\
\hline Фасовка продукции & 1 & 1 & 3 & 1 & 1 & 1 & 8 \\
\hline $\begin{array}{l}\text { Дизайн и оформление } \\
\text { продукции }\end{array}$ & 2 & 2 & 1 & 2 & 2 & 2 & 11 \\
\hline Внешний вид и консистенция & 4 & 4 & 4 & 5 & 5 & 4 & 26 \\
\hline Срок годности товара & & & & & & & 90 \\
\hline Итого & &
\end{tabular}


Если коэффициент конкордации окажется ниже $50 \%$, это свидетельствует о не высокой квалификации или о том, что показатели, характеризующие качество продукции недостаточно точно сформулированы, что усложнило восприятие их экспертами. В этом случае определяют квалификацию отдельных экспертов (тех из них, результаты которых резко отличаются от мнений основной группы) или заменяют их. Наряду с этим, пересматривают формулировку каждого из факторов на предмет их точности, что позволяет провести повторно данную оценку. Эксперты дают оценку не зависимо друг от друга, т.е. они не знакомы с результатами оценок предыдущих участников.

Коэффициент конкордации более $50 \%$, но менее $70 \%$ свидетельствует об умеренной степени согласованности мнений экспертов. Равенство коэффициента конкордации $70 \%$ и выше свидетельствует о высокой степени со-

гласованности мнений экспертов и возможности использования их в дальнейших расчеTax.

В рассматриваемом случае коэффициент конкордации составил $71,7 \%$, что указывает на высокую степень согласованности мнений экспертов, следовательно, результаты экспертной оценки могут быть использованы в дальнейших расчетах.

На основе полученных оценок вычисляются значения весовых коэффициентов по формуле:

$$
\boldsymbol{R}_{i}=\sum_{1}^{m} r_{i s} / \sum_{i=1}^{m} \sum_{s=1}^{n} r_{i s},
$$

где: $\mathrm{r}$ is- оценка эксперта степени влияния данного показателя на конкурентоспособность в баллах.

Весовые нормы качественных параметров продукции приведены в табл. 2.

Т а б ли ц а 2

Экспертные оценки коэффициентов весомости единичных показателей качества

\begin{tabular}{|l|c|}
\hline \multicolumn{1}{|c|}{ Единичные показатели качества } & Оценка коэффициента весомости \\
\hline Биохимический состав продукции & 0,311 \\
\hline Дизайн и оформление продукции & 0,09 \\
\hline Фасовка продукции & 0,188 \\
\hline Внешний вид и консистенция & 0,122 \\
\hline Срок годности товара & 0,289 \\
\hline Сумма & $\Sigma-1,000$ \\
\hline
\end{tabular}

Источник: разработано автором

Конкурентоспособность продукции определяется следующим образом: на первом этапе дается количественная оценка конкурентоспособности продукции по каждому из факторов. При этом количественная оценка конкурентоспособности дается как по отечественной продукции, так и по эталонной. Конкурентоспособность продукции по биохимическому составу определяется, как произведение значения данного показателя томат пасты произведенной в Узбекистане, и ее конкурента на весовую норму показателя, т.е. степени влияния его на конкурентоспособность. Подобные расчеты производятся, исходя из величин каждого показателя, влияющего на конкурентоспособность, и весовой его нормы.

За эталон качества продукции принимаются показатели товара произведенного лидером на мировом рынке.

На втором этапе дается комплексная оценка конкурентоспособности продукции, устанавливаемая, как ее сумма по каждому параметру. Расчеты приведены в табл. 3.

Из этих данных видно, что отечественная продукция (томат паста) по своим качественным параметрам превосходит продукцию конкурента на 114,4\%.

Значительное опережение отечественного товара продукции конкурента наблюдается за счет лучшего биохимического состава продукции и наличия различных видов фасовки, что позволяет учесть потребности большего числа потребителей. В то же время, отечественная продукция уступает конкуренту по такому показателю как внешний вид и консистенция, которая во многом зависит от усилий коллектива предприятия, производящего данный товар.

Данные табл. 3 показывают, что основными параметрами, значительно влияющими на конкурентоспособность являются: 
Т а б ли ц а 3

Оценка конкурентоспособности товара

\begin{tabular}{|c|c|c|c|c|c|c|}
\hline \multirow{2}{*}{$\begin{array}{c}\text { Параметры } \\
\text { качества товара }\end{array}$} & \multirow{2}{*}{$\begin{array}{l}\text { Весомость } \\
\text { показателя }\end{array}$} & \multicolumn{2}{|c|}{$\begin{array}{l}\text { Значения } \\
\text { параметров }\end{array}$} & \multicolumn{2}{|c|}{$\begin{array}{c}\text { Количественная } \\
\text { оценка конкурентос- } \\
\text { пособности товара }\end{array}$} & \multirow{2}{*}{$\begin{array}{l}\text { Соотноше- } \\
\text { ние кон- } \\
\text { курентоспо-- } \\
\text { собности }\end{array}$} \\
\hline & & $\begin{array}{l}\text { конку- } \\
\text { рент }\end{array}$ & $\begin{array}{c}\text { отечест- } \\
\text { венный } \\
\text { товар }\end{array}$ & $\begin{array}{c}\text { конку- } \\
\text { рент }\end{array}$ & $\begin{array}{c}\text { отечест- } \\
\text { венный } \\
\text { товар }\end{array}$ & \\
\hline $\begin{array}{l}\text { Биохимический } \\
\text { состав продукции }\end{array}$ & 0,311 & 28 & 32 & 8,708 & 9,952 & 1,143 \\
\hline $\begin{array}{l}\text { Дизайн и оформле- } \\
\text { ние продукции }\end{array}$ & 0,09 & 4,3 & 4 & 0,387 & 0,36 & 0,93 \\
\hline Фасовка продукции & 0,188 & 7 & 11 & 1,316 & 1,98 & 1,5 \\
\hline $\begin{array}{l}\text { Внешний вид и } \\
\text { консистенция }\end{array}$ & 0,122 & 10 & 9 & 1,22 & 1,098 & 0,9 \\
\hline $\begin{array}{l}\text { Срок годности } \\
\text { товара }\end{array}$ & 0,289 & 2 & 2 & 0,578 & 0,578 & 1 \\
\hline Сумма & 1,0 & & & 12,209 & 13,968 & 114,4 \\
\hline
\end{tabular}

Источник: разработано автором

- биохимический состав продукции, доля которой $(71,2 \%)$;

- фасовка продукции (14,2\%);

- внешний вид и консистенция (7,9\%)

- срок годности товара $(4,1 \%)$.

$(2,6 \%)$

- дизайн и оформление продукции

Важное место в конкурентоспособности товара отводится его цене. Анализ фактической себестоимости товара отечественного производителя позволил выявить его рост по сравнению с ценой конкурента на $15,8 \%$. Сопоставление цены товара с его качеством показал, что здесь имеются некоторые отклонения. Как свидетельствуют литературные источники, рост цены товара должен сопровождаться адекватным улучшением его качества. Для выявления данного вопроса авторами были произведены отдельные расчеты, которые показали, что при росте качественных параметров отечественной продукции на $14,4 \%$ по сравнению с томат пастой конкурента, цена его была выше, чем у конкурента на 15,8\%. Из приведенных выше данных видно, что стоимость (себестоимость 1 кг. томат пасты) отечественной продукции существенно опережает темпы роста качественных параметров, что отрицательно влияет на конкурентоспособность, т.е. отечественная продукция с учетом ценового фактора уступает конкуренту на 1,2 \% (конкурентоспособность томат пасты Узбекистана составляет 98,8\%). В то же время, здесь имеются значительные резервы в сокращении себестоимос- ти продукции. Для этих целей необходимо сократить все непроизводительные затраты как сырьевых ресурсов, так и энергетических, трудовых и т.д., о которых было упомянуто выше.

Расчеты показали, что обеспечение предприятия качественными сырьевыми ресурсами позволят сократить материальные затраты на производство каждого килограмма томат - пасты в среднем на 93,18 сум; затраты электроэнергии на единицу продукции сократятся на 8,4 сумм., воды - на 10,8 сум., трудовых затрат - на 4,2 сум. В результате цена одного килограмма томат пасты может быть сокращена на $16,7 \%$ от заводской стоимости, что позволит повысить конкурентоспособность по ценовому фактору. Снижению себестоимости так же способствует и согласованность действий всех звеньев логистической цепи, которая может быть достигнута разработкой экономических механизмов взаимодействия всех подразделений, входящих в состав логистической цепи.

В настоящее время конкурентоспособность отечественного товара с учетом ценового фактора составит $0,0186(13,968 / 754,15)$, а конкурента 0,0188 (12,209/651). Как видно, цена отечественного товара растет не адекватно его качеству, что становиться причиной низкой конкурентоспособности.

Ликвидация непроизводительных затрат позволит сократить себестоимость производства одного килограмма томат пасты до 628,21 суммов $(754,15 *(100-16,7)) / 100$, что 
ниже уровня цены конкурента на 3,5\%. Комплексная оценка конкурентоспособности отечественной продукции с учетом ценового фактора производилась на основе сопоставления себестоимости продукции к его качественному параметру $(651 / 12,209$ и 628.21/13,968). При снижении затрат на $16,7 \%$ данный параметр составит 44,97 сумм на единицу качества товара $(628,21 / 13,968)$.

В этом случае комплексная оценка конкурентоспособности отечественной продукции составит $118,6 \%(53,32 / 44,97)$, т.е. превысит конкурентоспособность товара другого производителя на $18,6 \%$.

Данная ситуация позволит предприятию - производителю более вольготно чувствовать себя на рынке ввиду того, что у него появляется более широкие возможности в предоставлении ценовых льгот покупателю из-за расширения диапазона между себестоимостью и ценой реализации товара. Этот диапазон будет ограничен ценой реализации товара и ее себестоимостью. В данном случае продавец может предоставить большие скидки при покупке больших партий товара, чего сделать конкурент не может в виду высокой себестоимости.

Выводы и перспективы дальнейших исследований. Учитывая те обстоятельства, что отечественная продукция значительно превосходит продукцию конкурентов по биохимическому составу, возможно, производить продукцию в широких диапазонах качества. В связи с этим, по нашему мнению, в процессе фасовки товара и его производства необходимо учитывать направления его использования, производя его с качественными различными характеристиками. Для дальнейшего промышленного потребления томатпаста может быть изготовлена с более высоким содержанием сухих растворимых веществ, витаминов, сахаров, кислотности и др., то есть концентрированной. В этом случае покупатель из того же объема сырья сможет произвести больше продукции в виде кетчупов и различных приправ, используя томат-пасты. Это позволит сэкономить собственные затраты на таре, транспортных рас-

\footnotetext{
Стаття надійшла

до редакції : 18.11.2018 p.
}

ходах, на погрузочно-разгрузочных операцияx.

\section{Литература}

1. Нишанбаев X. 3. Оценка экспортных возможностей плодоовощного комплекса / Х. 3. Нишанбаев, Г. А. Кариева // Иқтисодиёт ва таълим Ташкент. - 2003. - №2. - С. 117-121.

2. Нуруддинова А. Г. Развитие потенциала малого бизнеса как фактор повышения благосостояния населения и формирования спроса на потребительском рынке: Международная конференция «О роли и значении малого бизнеса и частного предпринимательства в реализации социально-экономической политики в Узбекистане» / А. Г. Нуруддинова. - Ташкент, 2013. Ч. 2. - C. 97-100.

3. Нуруддинова А. Г. Эффективное кадровое обеспечение инновационной деятельности как фактор повышения конкурентоспособности экономики: Материалы секционного заседания «Интеграция образования, науки и производства» IX Международного форума «Высокие технологии XXI века», 23 апреля 2008 г. / А. Г. Нуруддинова, Н. Х. Мирсалихова. - М: МГТУ, 2008. - С. 197-199.

\section{References}

1. Nishanbayev, H. Z. \& Karieva, G. A. (2003). Evaluation of the export potential of the fruit and vegetable complex. Economics and education Tashkent, 2, 117-121.

2. Nuruddinova, A. G. (2013). Development of the potential of small business as a factor in improving the welfare of the population and the formation of demand in the consumer market. International. Conference "On the role and importance of small business and private entrepreneurship in the implementation of socio-economic policy in Uzbekistan". Uzbekistan, Tashkent. Part 2, 97-100.

3. Nuruddinova, A. G. \& Mirsalikhova, N. Kh. (2008). Effective staffing of innovation as a factor in improving the competitiveness of the economy. Materials of the sectional meeting "Integration of education, science and production" of the IX International Forum "High Technologies of the XXI Century", April 23, 2008. Moscow: MSTU, 197-199.

\footnotetext{
Стаття прийнята

до друку: 29.03.2019 р.
}

Бібліографічний опис для цитування :

Асадуллина Н. Р. Комплексная оценка конкурентоспособности переработанной плодоовощной продукции / Н. Р. Асадуллина // Часопис економічних реформ. - 2019. - № 1 (33). - С. 6-12. 